\title{
FOODBORNE DISEASE SURVEILLANCE NEEDS IN AUSTRALIA: HARMONISATION OF MOLECULAR LABORATORY TESTING AND SHARING DATA FROM HUMAN, ANIMAL, AND FOOD SOURCES
}

\author{
Martyn Kirk \\ OzFoodNet \\ Commonwealth Department of Health and Ageing
}

Foodborne diseases cause significant morbidity and mortality in Australia and throughout the world. Outbreaks of foodborne disease often require investigators to collaborate across jurisdictional boundaries - even at times internationally. Notified cases of foodborne disease are only a small proportion of the total burden of foodborne disease affecting the community. Many pathogens that contaminate food are zoonotic in origin (that is, are transmitted to humans from lower vertebrates), although the pathway from animal to human via foods is complex and difficult to understand. This article describes how our ability to understand and control foodborne diseases in Australia can be enhanced through improving our surveillance datasets by harmonising methods for advanced microbiological testing of foodborne organisms, and sharing data obtained from human, food, and animal sources.

\section{BACKGROUND}

The World Health Organization and many countries around the world have recognised the importance of foodborne disease and the necessity of improving surveillance for this. ${ }^{1,2}$ Routine surveillance of foodborne disease relies on reports from doctors or clinical laboratories regarding people diagnosed with gastrointestinal or foodborne infections. In Australia, there are several infections that are notifiable to health agencies, including: Salmonella, Campylobacter, toxigenic E. coli, and listeriosis. ${ }^{3}$ These agencies maintain well-organised collections of data describing human infections, which have proven useful for determining trends and identifying outbreaks, particularly at the state and territory level and more recently at the national level.,

The nature of foodborne disease investigations has changed significantly, with more complex and wideranging investigations becoming the norm. ${ }^{2}$ Contemporary outbreaks are more geographically widespread than they were in the past, and may be solved with smaller numbers of cases. ${ }^{6}$ Increasingly, investigators rely on advanced microbiological evidence to supplement field epidemiology. ${ }^{6,7}$ The overriding goal of investigations is to prevent further cases, either by removing contaminated food from the marketplace, or by changing policy or practice to avoid future events of contamination. These changes represent a new paradigm in outbreak investigation (Table 1). ${ }^{8}$

Despite these developments in surveillance and investigation methods, there are still many areas for improvement. Each year health agencies investigate many notified infections and apparent outbreaks. In the investigation of some foodborne outbreaks, they may be able to identify the vehicle of infection, which is the specific food people ate before becoming ill. However, it is far more difficult to identify the original source of contamination, which may be an infected human or animal or a flaw in handling the food.

Of the 7,917 cases of laboratory-confirmed Salmonella infection notified to health departments in 2002, 543 cases were linked to foodborne or waterborne outbreaks (OzFoodNet, unpublished data). For certain infections, the 'success rate' of linking notifications with outbreaks may be considerably lower. For example, while Campylobacter is the most common enteric infection notified to health departments throughout Australiadespite it not being notifiable in New South Wales_-and

\section{TABLE 1}

THE CHANGING PARADIGM OF FOODBORNE DISEASE OUTBREAK INVESTIGATIONS

\begin{tabular}{|ll|}
\hline Old Strategy & New Strategy \\
\hline Culture all leftover foods & Develop and test hypotheses \\
Action based on pathogen in food & Evaluate exposure in ill and well \\
Assume someone broke the rules & Take action on statistics \\
\hline Goal & Goal \\
Assign blame & Prevent it happening again \\
Treat industry as a perpetrator & Treat industry as a collaborator \\
Be sure your evidence holds up in court & Be sure your data are scientifically valid \\
\hline
\end{tabular}

Source: Hedberg CW, Rigdon CE, Osterholm MT. White Paper on Applied Epidemiology. Food Safety and Inspection Service. ${ }^{8}$ 
in 2002 there were 14,716 notifications of infection; of these only 24 cases were subsequently linked to outbreaks.

In early 2001, Salmonella Typhimurium 170 infections increased dramatically in the eastern states of Australia, with case numbers rivalling the most common Salmonella serovars (Figure 1). Health departments conducted intensive investigation of over 100 cases, although no source was definitively identified. Hypothesis generating interviews of cases revealed that many had putative exposures to consumption of red meat and/or poultry and livestock contact. A trace-back investigation of foods mentioned by patients failed to identify any common vehicle for the increase. State and territory health departments investigated an additional 45 clusters of salmonellosis during 2002 where no source was identified. ${ }^{9}$ These investigations show the difficulty of identifying the cause of outbreaks, and that our strategies may need to be reviewed.

Enhancing our ability to correctly attribute infections to food vehicles and sources should also focus on combining epidemiological investigation of human cases, with data from advanced laboratory testing and hazard surveillance of animals and foodstuffs. Some potential improvements to surveillance of foodborne organisms are briefly discussed below.

\section{ADVANCED LABORATORYTESTING}

Most state and territory reference laboratories in Australia regularly characterise pathogens using advanced methods of analysis, such as serotyping, antimicrobal testing, and gene sequencing. Despite this, for some organisms there is a lack of standardisation of testing across Australia and the results may not find their way into surveillance datasets. This leads to inadequate epidemiological information at the jurisdictional level and difficulties interpreting national data.

Typing of Salmonella enterica using standard panels of antisera is an example of a very successful typing scheme that assists health departments identify outbreaks of foodborne disease. This success is due to the typing scheme being able to distinguish over 2000 epidemiologically-distinct serotypes that are stable over time. The success of Salmonella surveillance relies on an epidemiologically robust scheme that divides $S$. enterica into serotypes and phage types. The National Enteric Pathogen Surveillance Scheme (NEPSS) has collected data on serotypes and phage types infecting humans, animals, foods, and the environment, for many years. ${ }^{10}$ These data are a national resource that assists epidemiologists investigate outbreaks. The success of the scheme has relied on the cooperation of microbiological laboratories, and

\section{FIGURE 1}

REPORTS OF SALMONELLATYPHIMURIUM PHAGE TYPE 170, BY STATE OR TERRITORY AND MONTH OF ISOLATION, JANUARY 2001 TO DECEMBER 2002

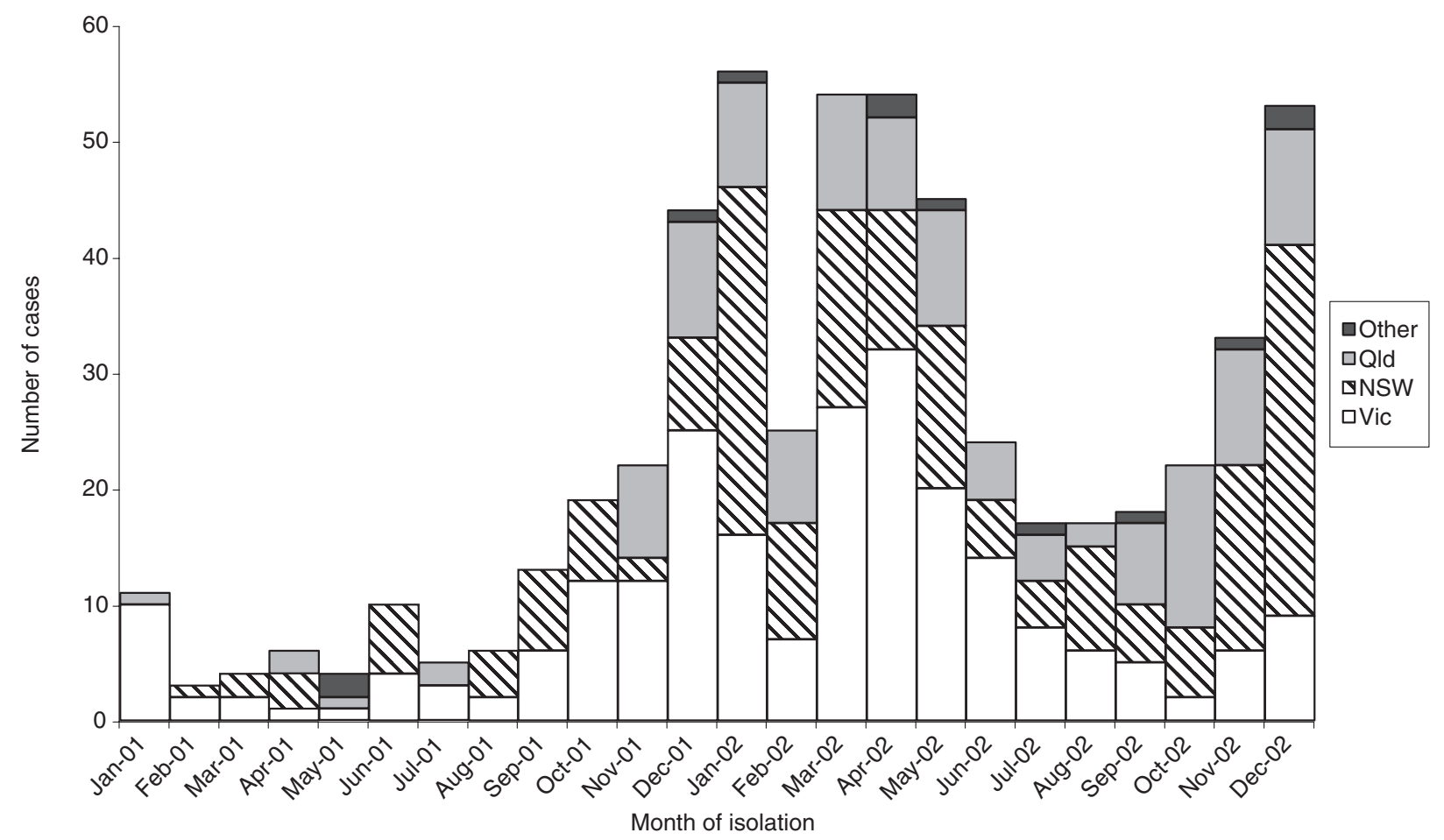

Source: Data from the National Enteric Pathogen Surveillance Scheme, March 2003. 
the existence of a robust typing system for these organisms.

The Centers for Disease Control and Prevention in Atlanta have developed the PulseNet system of surveillance for typing human isolates of Salmonella, Listeria, and E. coli O157:H7 using Pulsed Field Gel Electrophoresis (PFGE). ${ }^{11}$ PFGE is a technique based on the analysis of bacterial DNA, which allows the assignment of a characteristic genetic fingerprint. The PulseNet system relies on harmonised laboratory protocols for subtyping a restricted number of foodborne organisms, and comparing the results to detect outbreaks with a common source. The system has proven valuable for identifying the source of outbreaks and provides a library of DNA patterns for future reference.

The PulseNet system has been instituted in Canada. Europe also commonly uses PFGE as a complementary tool to traditional phenotypic methods of analysis. This has developed into a similar network-Salm-gene-to allow the exchange of PFGE profiles for common Salmonella serotypes across Europe. ${ }^{2,13}$ There are current plans to increase coverage of these PFGE networks to other regions of the globe, including Asia and the Pacific.

In 2000, the Australian Public Health Laboratory Network (PHLN) conducted a trial of sharing PFGE patterns of Listeria isolates (personal communication from Geoff Hogg, University of Melbourne, 25 March 2003). Ideally, Australia would build on this trial to routinely type and share molecular typing information due to the serious nature of listeriosis. The rapid sharing of typing data could improve the detection of clusters of illness that are spread across different geographical regions. This would require resources and harmonisation of PFGE typing methods in state and territory public health laboratories. PFGE surveillance of these infections is desirable for the following reasons:

- Listeria has the potential to cause widely distributed outbreaks;

- the PHLN trial demonstrated the feasibility of such a typing network in Australia;

- the small numbers of isolates for testing each year (approximately 60) represents a manageable workload for laboratories.

The key features of this surveillance are that it should be timely, accurate, and able to assist with detection of clusters and outbreaks. Harmonised PFGE typing could also assist jurisdictions investigating multi-state outbreaks of salmonellosis.

\section{FOOD SURVEILLANCE}

While Australian health agencies regularly survey the microbiological quality of foods for human consumption, few conduct true surveillance of food hazards. 'Hazard surveillance' is defined as the 'assessment of the occurrence of, distribution of, and the secular trends in levels of hazards (such as toxic chemical agents, physical agents, biomechanical stressors, as well as biological agents) responsible for injury'. ${ }^{13}$ It is important that collection of hazard data is ongoing and that the sampling frame is known. The aim of 'hazard surveillance' is to identify trends and emerging patterns that may be associated with human disease. However, in contrast to surveillance of human disease, 'hazard surveillance' is unlikely to identifty the occurrence of foodborne disease outbreaks.

The food supply is extremely complex and difficult to sample and test in a representative fashion. Ongoing systematic data collection describing the microbiological quality of foods is sorely lacking in Australia, despite health departments regularly conducting surveys of specific foods. One source of surveillance data on potential food hazards in Australia is the Imported Foods Database, coordinated by the Australian Quarantine and Inspection Service. Unfortunately, the usefulness of this database to health agencies is limited, due to the heterogeneous nature of imported foods tested, and because the contamination of most imported foods with human pathogens is very rare. $^{14}$

To conduct proper hazard surveillance of foods could prove very costly. An alternative would be to conduct simple surveillance of a few foods in an ongoing fashion. This might require jurisdictions to extend targeted surveys to run over several years and widen the sampling frame to increase the representativeness of the data. Short-term surveys of retail meats focussing on the prevalence of Salmonella and Campylobacter have proven useful to support policy development. ${ }^{15,16}$ The Australia Capital Territory Health Services conducted two surveys of retail meats in 1995-96 and 1999-2000 and found that for retail chicken meats Campylobacter prevalence increased from 12.3 per cent to 20.6 per cent. ${ }^{15}$ The survey also found that 41 per cent of chicken was contaminated with Salmonella, although a large proportion of isolates were the Sofia serotype which is usually only mildly pathogenic for humans. Internationally, food regulators and health agencies have used the data arising from these food surveys to inform policy, particularly in relation to the development of antibiotic resistance in isolates of animal origin. ${ }^{17}$

This surveillance of meats at retail sale may prove to be an indicator of the quality of meats at farms and abattoir processing facilities. In the absence of animal surveillance data, information on contamination of retail foods could reflect exposure to pathogens for Australian consumers, and provide impetus for more integrated monitoring with the agricultural sector.

\section{ANIMAL SURVEILLANCE}

Many foodborne diseases have a zoonotic basis, and are commonly associated with foods of animal origin, the use of manure for fertilisers, or direct contact with infected animals. An example of this was an investigation into a 
cluster of cases of Salmonella Typhimurium 170 occurring in October 2002. The source of the outbreak was identified as hatching chickens at a childcare centre, which was traced back to the flocks of chickens laying eggs (R. Stafford, personal communication, 12 March 2002). The investigation of this zoonotic outbreak provides important clues as to the source of the multi-state increase of these infections earlier in 2002 that was probably due to contaminated foods of animal origin (Figure 1).

Health agencies commonly use available data to inform investigations of sporadic infections and outbreaks due to these pathogens. The most commonly used data from animals, foods, and the environment, are those collected by the NEPSS and the Australian Salmonella Reference Laboratory databases. The National Enteric Pathogens Surveillance System dataset is housed at the Microbiological Diagnostic Unit at the University of Melbourne and is funded by the Commonwealth Department of Health and Ageing and state and territory health departments. The Australian Salmonella Reference Laboratory database is located at the Institute of Medical and Veterinary Science in Adelaide. These surveillance datasets record important information about the occurrence of specific Salmonella serovars and phage types, but the data are not representative due to the ad hoc nature of sampling, typing, and reporting. The National Enteric Pathogens Surveillance System also contains important information about antibiotic resistance of Salmonella, which is of vital national interest. Another important source of information can come from monitoring animal feeds, which are also collected in the National Enteric Pathogens Surveillance System. ${ }^{19}$

Industry groups collect information on the occurrence of potential human pathogens in animals, although these may not be available to health investigators in a timely fashion. Often the results are not typed to an adequate level, as there is no treatment benefit to the affected animals. Primary industries are changing to allow more access to their data, although there are still sensitivities surrounding the isolation of human pathogens in foodproducing animals.

The Rural Industries Research and Development Corporation - a statutory authority formed in 1990 under the Primary Industries and Energy Research and Development Act 1989-recently commissioned a report examining surveillance and response options for the Australian egg industry to monitor for the incursion of Salmonella Enteritidis $4 .{ }^{20}$ Human infections of this phage type of $S$. Enteritidis are rare in Australia, in contrast to many other countries where internal contents of eggs are contaminated. The proposed surveillance for Australia involves collecting a set number of drag swabs each month from sheds housing chickens used for breeding and laying eggs. This would only occur in larger production facilities, but the program is designed to detect contamination at moderate levels and provide insight to Salmonella serovars affecting the poultry and egg industries.

Ideally, government agencies with agricultural responsibilities would encourage and facilitate this type of surveillance of food-producing animals. There are significant costs associated with animal surveillance, but this may be offset by the cost savings of preventing disease in animals and humans. ${ }^{21}$ It is important to recognise that these data on animals and the environment provide information on potential sources of foodborne disease, but rarely do they reveal specific foods responsible for outbreaks. Each investigation into foodborne disease outbreaks requires robust epidemiological assessment for possible vehicles, and a trace-back investigation to confirm the original source of contamination. ${ }^{2}$

\section{INTEGRATING SURVEILLANCE}

Sweden and Denmark are probably the best-known examples of countries collecting systematic data on Salmonella and Campylobacter from human, animals, and food sources over many years. ${ }^{21-23}$ Integrating surveillance data from these three sources requires continuous intensive surveys of the microbiological quality of animal herds and foodstuffs for retail sale. The predominant serotypes or subtypes detected in these surveys are then compared to the predominant types in humans. This type of surveillance is quite costly, but yields important insights for the control of foodborne disease. Due to the intensive ongoing monitoring of Salmonella in foods and animal herds in these countries, they can attribute human infections with common serotypes and phage types to different commodity groups of foods. Another Nordic country-Iceland-was able to observe major declines in human Campylobacter infections and decreases in contamination of poultry for retail sale following significant interventions in the poultry industry and consumer education campaigns. ${ }^{24}$

The high incidence of Salmonella and Campylobacter infections in humans makes integration of surveillance urgent. Integration on the scale practiced by Denmark and Sweden is likely to be very difficult in Australia, due to its geographical diversity and regulatory environment. However, collecting and sharing these data in a timely fashion should be a long-term goal to control diseases transmitted by animals, foods, and environment. This goal was recently recognised as a priority by the Food Regulation Standing Committee, the peak body for Government food safety policy in Australia.

\section{OUTCOMES}

Government agencies should consider collecting new surveillance data on animals and foods, but not for regulatory enforcement purposes. The main objective for longer-term surveillance must be to support the prevention of disease in humans and control of contamination in 
animals and foods. During disease investigations it is important to be aware of the potential for these diseases to have a zoonotic reservoir, which may have a complex pathway via food to humans. There are some fundamental differences in the surveillance for humans, foods, and animals, which include differences in the nature of sampling for pathogens. For Australia to improve its ability to understand and control foodborne disease, we need to work towards developing integrated surveillance and a systematic approach to molecular typing of infectious organisms that are potentially transmitted by food.

\section{ACKNOWLEDGEMENTS}

Fred Angulo from the Centers for Disease Control and Prevention, and Mark Veitch from the Microbiological Diagnostic Unit Public Health Laboratory, provided helpful comments on a draft of this article. The OzFoodNet program of work is an initiative of the Commonwealth Department of Health and Ageing.

\section{REFERENCES}

1. World Health Organization. Global surveillance of foodborne disease: Developing a strategy and its interaction with risk analysis. Report of a WHO consultation, Geneva, Switzerland 26-29 November 2001. WHO/CDS/CSR/EPH/2002.21, Geneva 2002.

2. O'Brien SJ, de Valk H. Salmonella—'Old' organism, continued challenges. Eurosurveillance 2003; 8: 29-31.

3. Lin M, Roche P, Spencer J, Milton A, et al. Australia's notifiable diseases status, 2000. Annual report of the National Notifiable Diseases Surveillance System. Commun Dis Intell 2002; 26: 118-203

4. Hall GV, D'Souza RM, Kirk MD. Foodborne disease in the new millennium: Out of the frying pan and into the fire? Med J Aust 2002; 177: 614-618.

5. Kaldor J, Cameron AS, Harris A, Mead P, Kennedy M. Report of the External Review Team-OzFoodNet. Canberra: Commonwealth Department of Health and Ageing, 2002.

6. Sobel J, Griffin PM, Slutsker L, Swerdlow DL, Tauxe RV. Investigation of Multistate Foodborne Disease Outbreaks. Public Health Rep 2002; 117: 8-18.

7. van Pelt W, van der Zee H, Wannet WJB, et al. Explosive increase of Salmonella Java in poultry in the Netherlands: Consequences for public health. Eurosurveillance 2003; 8:315.

8. Hedberg CW, Rigdon CE, Osterholm MT. White Paper on Applied Epidemiology. Food Safety and Inspection Service. Docket No. 01-020N www.fsis.usda.gov/OPPDE/rdad/ FRPubs/01-020N/EPIWhitePaper.pdf. Accessed on 14 March 2003.

9. Anon. Foodborne disease in Australia: incidence, notifications and outbreaks. Annual report of the OzFoodNet network, 2002. Commun Dis Intell 2003;27:209-43.
10. Powling J, Lightfoot D, Veitch M, Hogg G. Human Annual Report 2001-National Enteric Pathogen Surveillance Scheme. Melbourne: Microbiological Diagnostic Unit Public Health Laboratory, University of Melbourne, 2002.

11. Swaminathan B, Barrett TJ, Hunter SB, Tauxe RV. PulseNet: The molecular subtyping network for foodborne bacterial disease surveillance, United States. Emerg Infect Dis 2001; 7: 382-9.

12. Peters TM, Maguire C, Threlfall EJ, Fisher IST, Gill N, Gatto A. The Salm-gene project-A European collaboration for DNA fingerprinting for food-related salmonellosis. Eurosurveillance 2003; 8: 46-50.

13. Thacker SB, Stroup DF, Parrish RG, Anderson HA. Surveillance in environmental public health: Issues, systems, and sources. Am J Public Health. 1996; 86: 633-8.

14. Bull AL, Crerar SK, Beers MY. Australia's Imported Food Program-A valuable source of information on microorganisms in foods. Commun Dis Intell 2002; 26: 28-32.

15. Millard G, Rockliff S. Microbiological Status Of Raw Chilled Chicken July 1999-August 2000. Health Protection Service Food Survey Report 1999-2000. Canberra: Australian Capital Territory Department of Health, Housing and Community Care, 2001.

16. Department of Human Services South Australia. Meat Survey Summary. Internal Report. Adelaide: Department of Human Services South Australia, 2002 (unpublished).

17. Wilson IG. Salmonella and campylobacter contamination of raw retail chickens from different producers: A six year survey. Epidemiol Infect 2002; 129: 635-45.

18. White DG, Shaqhua Z, Sudler R, et al. The isolation of Antibiotic-Resistant Salmonella from Retail Ground Meats. New Engl J Med 2001;345: 1147-54.

19. Crump JA, Griffin PM, Angulo FJ. Bacterial contamination of animal feed and its relationship to human foodborne illness. Clin Infect Dis 2002; 35: 859-65.

20. Sergeant ESG, Grimes TM, Jackson CAW, Baldock FC, Whan IF. Salmonella enteritidis surveillance and response options for the Australian egg industry. Rural Industries Research and Development Corporation Publication No. 03/006, January 2003. www.rirdc.gov.au/reports/EGGS/03-006.pdf accessed on 23 June 2003.

21. Wegener HC, Hald T, Wong DLF, Madsen M, Korsdaard H, Bager F, Gerner-Smidt P, Molbek K. Salmonella Control Programs in Denmark. Emerg Infect Dis 2003; 9:774-780.

22. Hald T, Brandsted T, Dresling A, Ethelberg S (editors). The Annual Report of Zoonoses in Denmark 2001. Ministry of Agriculture and Fisheries. 2002 www.vetinst.dk/file/WEBAnnual\%20Report.pdf accessed on 8 October 2002.

23. Hofshagen M, Aavitsland P, Kruse H. (editors). Trends and Sources of Zoonotic Agents in Animals, Feedingstuffs, Food, and Man in Norway 2001. The Norwegian Zoonoses Centre 2002. www.zoonose.no/Zoonoserapport01-eng.pdf accessed on 8 October 2002.

24. Stern NJ, Hiett KL, Alfredsson GA et. al. Campylobacter spp. in Icelandic poultry operations and human disease. Epidemiol Infect 2003; 130:23-32. 